EISSN: 2706 -7947 ISSN: 2077- 4613

DOI: $10.36632 / \mathrm{mejas} / 2021.11 .4 .66$

Journal homepage: www.curresweb.com

Pages: 859-865

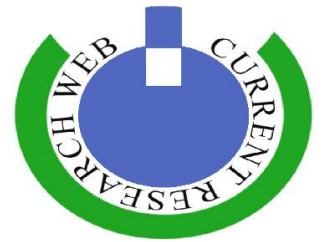

\title{
Feeding Practice, Oral Hygiene Habits and Its Relation to Dental Caries among Sample of School Aged Egyptian Children
}

\section{Yomna Darwish ${ }^{1}$, Nancy A. Khattab², Mohammed Abou El-Yazeed ${ }^{3}$, Nayera E. Hassan ${ }^{4}$ and Tamer G. Rashed ${ }^{5}$}

${ }^{1}$ Assistant Researcher, Orthodontics and Pediatric Dentistry Department, National Research Centre, 33 El Buhouth St., 12622 Dokki, Giza, Egypt.

${ }^{2}$ Prof. of Dental Anthropology, Dental Anthropology Department, Faculty of African Postgraduate Studies, Cairo University, Egypt.

${ }^{3}$ Prof. of Pediatric Dentistry, Head of Orthodontics and Pediatric Dentistry Department, National Research Centre, 33 El Buhouth St., 12622 Dokki, Giza, Egypt.

${ }^{4}$ Prof. of Biological Anthropology, Head of Biological Anthropology Department, National Research Centre, 33 El Buhouth St., 12622 Dokki, Giza, Egypt.

${ }^{5}$ Lecturer of Biological Anthropology, Biological Anthropology Department, Faculty of African Postgraduate Studies, Cairo University, Egypt.

\author{
Received: 29 July $2021 \quad$ Accepted: 25 August $2021 \quad$ Published: 30 Oct. 2021
}

\begin{abstract}
Background: Dental caries is a global public health problem and influence the overall health of children. The risk factors for caries include biological, socio-behavioral and environmental factors. This cross-sectional study assessed dental caries and their associations with oral hygiene practices and eating habits among Egyptian children. Methods: This cross sectional study conducted in Cairo Egypt, the sample consisted of 750 primary school children aged 6-12 years, oral examination was done according to WHO criteria, and eating and oral hygiene questionnaires was completed by their parents.

Results: Distribution of dental caries was higher in children who ate snacks and sweets and don't brush their teeth, higher in females than males, and in group I (6-9) than group II (9-12). Conclusion: there was weak positive significant difference between dental caries and dental office consultation and tooth brushing renewal frequency, but there was insignificant correlation between dental caries and other eating and oral hygiene habits.
\end{abstract}

Keywords: dental caries, oral hygiene habits and eating habits.

\section{Introduction}

Dental caries is a multifactorial problem affected by a collection of factors such as orodental hygiene, salivary characteristics, socioeconomic status, low awareness among parents, ethnicity, age, dental anatomy and arrangement, limited access to dental health-care services, and hereditary factors, (Bahrololoomi et al., 2017).

Dental caries is a biofilm-mediated, diet modulated, multifactorial, non-communicable, dynamic disease resulting in mineral loss of dental hard tissues. It is determined by biological, behavioral, psychosocial, and environmental factors. Caries lesion develops as a consequence of this process, (Machiulskienea et al., 2020).

Nutrition plays an important role in the epidemic of obesity. Beside obesity, high carbohydrate consumption frequency and overconsumption of glucoses are reported as effective for caries development (Sakeenabia et al., 2012).

Corresponding Author: Yomna Darwish, Orthodontics and Pediatric Dentistry Department, National Research Centre, 33 El Buhouth St., 12622 Dokki, Giza, Egypt.

E-mail: dr.yomna.ahmed@gmail.com 


\section{Subject and method}

This cross sectional study was conducted in Cairo Egypt. The study sample included 750 school age children of both sexes. Samples were collected from primary schools and hospitals, and children aged between 6-9 years and 9-12 years ( 250 male, 320 female) and 9-12 years ( 85 male, 95 female).

\section{- Inclusion criteria}

Apparently healthy children free, from genetic disorders, and any systemic or chronic diseases (from school medical insurance files).

\section{- Exclusion criteria}

- Children with history of any chronic or genetic diseases.

- Children less than 6 years or more than 9 years.

- Non Egyptian children.

\section{Every child was subjected to}

\section{1- Clinical examination of the children}

\section{A- Dental examination}

Dental examination of children was done by using light torch with a disposable probe and mouth mirror. Visible caries on tooth surface were registered.

A semi structured chart was designed for detection of dental caries according to WHO (2013) criteria, using the dft (decayed, filled primary teeth) and DMFT (Decayed, Filled, Missed Permanent teeth) values. Missing primary teeth $(\mathrm{m}=$ missing) will not be registered because the examined children were expected to be in the mixed dentition stage making it hard to identify the exact reason for missing primary teeth according to Ahmed and Abuaffan, (2015).

\section{B- Children's diet (eating habit) and oral hygiene habits}

Children's diet and oral hygiene habits were assessed according to Baccouche et al. (2017), in terms of meals, sweets consumption and oral hygiene.

\section{Results}

\subsection{Association between dental caries, eating and oral habits \\ I. Eating habits}

In question 1(Q1) "yes" answer was significantly higher than "no" answer in both categories of DMF and dft in both groups. In Q2, answer "yes" was significantly higher than answer "no" in both DMF and dft categories in both groups. In Q 3 answer "2" was significantly the highest while answer "1" was significantly the lowest in both DMF \& dft categories in both groups except in "with caries" in group II dft, "3" was significantly the lowest as it is shown in table 1.

\section{Sweet habits}

In Q4 "yes" answer was significantly higher than "no" answer in both categories of DMF and dft in both groups. In Q 5, answer "1" was significantly the highest in DMF (no caries 43.8\%) category in group I, (no caries category $33.8 \%$ and with caries category $36.7 \%$ ) in group II, while answer " 3 " was significantly the highest in (with caries) category in group I. For dft, answer "1" was significantly the highest in group I for both categories $(56.7 \%$ no caries, $35.2 \%$ with caries), in group II no caries category, "2" was the highest $39.4 \%$, while " 3 " was the highest in with caries category $37.5 \%$. While (every week) was the lowest in DMF and dft in both groups. In Q6 (chocolate) was significantly the highest in DMF and dft except in DMF (no caries) category group II (others) was the highest and in dft (no caries) category group II (more than one type) was the highest. (Candy) was the lowest in DMF and $\mathrm{dft}$ except in DMF, (no caries) category group II and dft (with caries) category, (biscuit) was the lowest as it is shown in table 2 . 
Table 1: Association between dental caries and eating habits in both groups of Egyptians

\begin{tabular}{|c|c|c|c|c|c|c|c|c|c|c|c|c|}
\hline & & & \multicolumn{5}{|c|}{ Group I } & \multicolumn{5}{|c|}{ Group II } \\
\hline & & & \multicolumn{5}{|c|}{ 6-9 years } & \multicolumn{5}{|c|}{$>9-12$ years } \\
\hline & & & \multicolumn{2}{|c|}{ No caries } & \multicolumn{2}{|c|}{ With caries } & \multirow[b]{2}{*}{$\mathbf{r}$} & \multicolumn{2}{|c|}{ No caries } & \multicolumn{2}{|c|}{ With caries } & \multirow[t]{2}{*}{$\mathbf{r}$} \\
\hline & & & $\mathbf{N}$ & $\%$ & $\mathbf{N}$ & $\%$ & & $\mathbf{N}$ & $\%$ & $\mathbf{N}$ & $\%$ & \\
\hline \multirow{10}{*}{ DMF } & Q1 & No & 150 & 35.1 & 37 & 25.9 & & 17 & 23.9 & 34 & 31.2 & \\
\hline & 3 meals & Yes & 277 & 64.9 & 106 & 74.1 & ---- & 54 & 76.1 & 75 & 68.8 & ---- \\
\hline & per day & P value & \multicolumn{2}{|c|}{$0.001 *$} & \multicolumn{2}{|c|}{$0.001 *$} & & \multicolumn{2}{|c|}{0.001} & \multicolumn{2}{|c|}{$0.001 *$} & \\
\hline & Q2 & No & 34 & 8 & 14 & 9.8 & & 8 & 11.3 & 10 & 9.2 & \\
\hline & Snaking & Yes & 393 & 92 & 129 & 90.2 & ----- & 63 & 88.7 & 99 & 90.8 & ------- \\
\hline & & $P$ value & \multicolumn{2}{|c|}{$0.001 *$} & \multicolumn{2}{|c|}{$0.001 *$} & & \multicolumn{2}{|c|}{$0.001 *$} & \multicolumn{2}{|c|}{$0.001 *$} & \\
\hline & Q3 & 1 & 88 & 20.6 & 20 & 14 & \multirow{4}{*}{0.08} & 10 & 14.1 & 22 & 20.2 & \multirow{4}{*}{0.01} \\
\hline & Number & 2 & 251 & 59 & 79 & 55.3 & & 47 & 66.2 & 65 & 59.7 & \\
\hline & of & 3 & 87 & 20.4 & 44 & 30.8 & & 14 & 19.7 & 22 & 20.2 & \\
\hline & snaking & $P$ value & \multicolumn{2}{|c|}{0.001} & \multicolumn{2}{|c|}{$0.001 *$} & & \multicolumn{2}{|c|}{$0.001 *$} & \multicolumn{2}{|c|}{$0.001 *$} & \\
\hline \multirow{10}{*}{ dft } & Q1 & No & 38 & 36.5 & 150 & 32.2 & & 24 & 31.6 & 27 & 26 & \\
\hline & 3 meals & Yes & 66 & 63.5 & 316 & 67.8 & ----- & 52 & 68.4 & 77 & 74 & --- \\
\hline & per day & $P$ value & \multicolumn{2}{|c|}{$0.001 *$} & \multicolumn{2}{|c|}{$0.001 *$} & & \multicolumn{2}{|c|}{$0.001^{*}$} & \multicolumn{2}{|c|}{$0.001 *$} & \\
\hline & Q2 & No & 12 & 11.5 & 36 & 7.7 & & 7 & 9.2 & 12 & 11.5 & \\
\hline & Snaking & Yes & 92 & 88.5 & 430 & 92.3 & ------ & 69 & 90.8 & 92 & 88.5 & ----- \\
\hline & & $P$ value & & & & & & & & & & \\
\hline & Q3 & 1 & 17 & 16.3 & 92 & 19.7 & & 5 & 6.6 & 27 & 26 & \\
\hline & Number & 2 & 65 & 62.5 & 265 & 56.9 & & 58 & 76.3 & 55 & 52.8 & \\
\hline & of & 3 & 22 & 21.2 & 109 & 23.4 & 0.06 & 13 & 17.1 & 22 & 21.2 & 0.019 \\
\hline & snaking & $P$ value & & & & & & & & & & \\
\hline
\end{tabular}

Table 2: Comparison between dental caries and sweet habits in both groups of Egyptians

\begin{tabular}{|c|c|c|c|c|c|c|c|c|c|c|c|c|}
\hline & & & \multicolumn{5}{|c|}{ 6-9 years } & \multicolumn{5}{|c|}{$>9-12$ years } \\
\hline & & & \multicolumn{2}{|c|}{ No caries } & \multicolumn{2}{|c|}{ With caries } & \multirow[b]{2}{*}{$\mathbf{r}$} & \multicolumn{2}{|c|}{ No caries } & \multicolumn{2}{|c|}{ With caries } & \multirow[t]{2}{*}{$\overline{\mathbf{r}}$} \\
\hline & & & $\mathbf{N}$ & $\%$ & $\mathbf{N}$ & $\%$ & & $\mathbf{N}$ & $\%$ & $\mathbf{N}$ & $\%$ & \\
\hline \multirow{16}{*}{ DMF } & Q4 & No & 14 & 3.3 & 5 & 3.5 & & 2 & 2.8 & 9 & 8.3 & \multirow{3}{*}{----- } \\
\hline & Sweet's & Yes & 413 & 96.7 & 138 & 96.5 & \multirow{2}{*}{----- } & 69 & 97.2 & 100 & 91.7 & \\
\hline & consumption & $P$ value & \multicolumn{2}{|l|}{$0.001 *$} & \multicolumn{2}{|c|}{$0.001 *$} & & \multicolumn{2}{|c|}{$0.001 *$} & \multicolumn{2}{|c|}{$0.001 *$} & \\
\hline & \multirow{5}{*}{$\begin{array}{l}\text { Number of sweets } \\
\text { consumption per } \\
\text { day }\end{array}$} & 1 & 187 & 43.8 & 36 & 25.2 & \multirow{5}{*}{$\begin{array}{c}0.00 \\
1\end{array}$} & 24 & 33.8 & 40 & 36.7 & \multirow{5}{*}{0.009} \\
\hline & & 2 & 112 & 26.2 & 44 & 30.8 & & 24 & 33.8 & 27 & 24.8 & \\
\hline & & 3 & 124 & 29 & 58 & 40.6 & & 20 & 28.2 & 39 & 35.8 & \\
\hline & & Every & 4 & 0.9 & 5 & 3.5 & & 1 & 1.4 & 3 & 2.8 & \\
\hline & & week & & & & & & & & & & \\
\hline & & P value & $0.001^{*}$ & & 0.00 & & & 0.00 & & 0.00 & & \\
\hline & & Chocolate & 141 & 33 & 47 & 32.9 & & 21 & 29.6 & 34 & 31.2 & \\
\hline & & Candy & 24 & 5.6 & 9 & 6.3 & & 13 & 18.3 & 7 & 6.4 & \\
\hline & Q6 & Biscuit & 36 & 8.4 & 14 & 9.8 & & 3 & 4.2 & 15 & 13.8 & \\
\hline & Nature of sweets & Others & 116 & 27.2 & 34 & 23.8 & 0.06 & 24 & 33.8 & 26 & 23.9 & 0.036 \\
\hline & & More & 110 & 25.8 & 39 & 27.3 & & 10 & 14.1 & 27 & 24.8 & \\
\hline & & $\begin{array}{c}\text { than } 1 \\
\text { type }\end{array}$ & & & & & & & & & & \\
\hline & & $P$ value & $0.001 *$ & & 0.00 & & & 0.00 & & 0.00 & & \\
\hline \multirow{15}{*}{ dft } & & No & 4 & 3.8 & 15 & 3.2 & & 3 & 3.9 & 7 & 6.7 & \\
\hline & Sweet's & Yes & 100 & 96.2 & 451 & 96.8 & ----- & 73 & 96.1 & 97 & 93.3 & ---- \\
\hline & consumption & $P$ value & $0.001 *$ & & \multicolumn{2}{|c|}{$0.001 *$} & & \multicolumn{2}{|c|}{$0.001 *$} & \multicolumn{2}{|c|}{$0.001 *$} & \\
\hline & \multirow{5}{*}{$\begin{array}{c}\text { Q5 } \\
\text { Number of sweets } \\
\text { consumption per } \\
\text { day }\end{array}$} & 1 & 59 & 56.7 & 164 & 35.2 & \multirow{5}{*}{0.13} & 24 & 31.6 & 31 & 29.8 & \multirow{5}{*}{0.05} \\
\hline & & 2 & 21 & 20.2 & 136 & 29.2 & & 30 & 39.4 & 31 & 29.8 & \\
\hline & & 3 & 24 & 23.1 & 158 & 33.9 & & 20 & 26.3 & 39 & 37.5 & \\
\hline & & Every & 0 & 0 & 8 & 1.7 & & 2 & 2.6 & 3 & 2.9 & \\
\hline & & $\begin{array}{c}\text { week } \\
\text { P value }\end{array}$ & $0.001 *$ & & 0.00 & & & 0.00 & & $0.0 c$ & & \\
\hline & & Chocolate & 46 & 44.2 & 143 & 30.7 & & 19 & 25 & 36 & 34.6 & \\
\hline & Q6 & Candy & 3 & 2.9 & 29 & 6.2 & & 7 & 9.2 & 14 & 13.5 & \\
\hline & Nature of sweets & Biscuit & 5 & 4.8 & 44 & 9.4 & & 8 & 10.5 & 10 & 9.6 & \\
\hline & & Others & 36 & 34.6 & 114 & 24.5 & & 20 & 26.3 & 29 & 27.9 & 0102 \\
\hline & & more & 14 & 13.5 & 136 & 29.2 & 0.09 & 22 & 28.9 & 15 & 14.4 & 0.103 \\
\hline & & $\begin{array}{c}\text { than } 1 \\
\text { type }\end{array}$ & & & & & & & & & & \\
\hline & & $P$ value & $0.001 *$ & & 0.00 & & & 0.00 & & 0.00 & & \\
\hline
\end{tabular}




\section{Oral hygiene habits}

In Q7, "never" was significantly the highest in the DMF (42.2\% no caries, $49.7 \%$ with caries in group I and $64.8 \%$ no caries, $57.8 \%$ with caries in group II) and dft ( $47.1 \%$ no caries, $43.3 \%$ with caries in group I and $64.5 \%$ no caries, $57.7 \%$ with caries in group II), while " 3 " was significantly the lowest in DMF (1.6\% no caries, $1.4 \%$ with caries in group I and $1.4 \%$ no caries, $0 \%$ with caries in group II) and in $\mathrm{dft}(1.9 \%$ no caries, $1.9 \%$ with caries in group I and $2.6 \%$ no caries, $0 \%$ with caries in group II ). In Q 8, "> 6 m" was significantly the highest in DMF (51.5\% no caries, $65 \%$ with caries in group I and $49.3 \%$ no caries, $49.3 \%$ with caries in group II) and dft (47.1\% no caries, $43.3 \%$ with caries in group I and $64.5 \%$ no caries, $57.7 \%$ with caries in group II), while " $<3$ " was significantly the lowest in DMF (22.2\% in no caries group I, $16.9 \%$ no caries and $22 \%$ with caries group II) and dft except (3-6) was the lowest in with caries group I in DMF (13.3\%) and dft (22.1\%). In Q 9, "never" was significantly the highest in DMF and dft except in DMF (with caries) category in group (49\%) and group II (48.6\%), and in $\mathrm{dft}$ (with caries) category in group I and both categories in group II " $<1$ " was the highest, while "each year" was the lowest in DMF and dft except in (with caries) group I in DMF and with caries group I in $\mathrm{dft}(<2)$ was the lowest as it is shown in table 3.

Table 3: Comparison between dental caries and oral hygiene habits in both groups of Egyptians

\begin{tabular}{|c|c|c|c|c|c|c|c|c|c|c|c|c|}
\hline & \multicolumn{5}{|c|}{ 6-9 years } & \multicolumn{4}{|c|}{$>9-12$ years } & \multirow{3}{*}{$\mathbf{r}$} \\
\hline & & & \multicolumn{2}{|c|}{ No caries } & \multicolumn{2}{|c|}{ With caries } & \multirow[t]{2}{*}{$\mathbf{r}$} & \multicolumn{2}{|c|}{ No caries } & \multicolumn{2}{|c|}{ With caries } & \\
\hline & & & $\mathbf{N}$ & $\%$ & $\mathbf{N}$ & $\%$ & & $\mathbf{N}$ & $\%$ & $\mathbf{N}$ & $\%$ & \\
\hline \multirow{15}{*}{ DMF } & \multirow{5}{*}{$\begin{array}{l}\text { Q7 } \\
\text { Dental } \\
\text { brushing } \\
\text { frequency }\end{array}$} & Never & 180 & 42.2 & 71 & 49.7 & \multirow{5}{*}{-0.06} & 46 & 64.8 & 63 & 57.8 & \multirow{5}{*}{-0.01} \\
\hline & & 1 & 177 & 41.5 & 51 & 35.7 & & 12 & 16.9 & 31 & 28.4 & \\
\hline & & 2 & 63 & 14.8 & 19 & 13.3 & & 12 & 16.9 & 15 & 13.8 & \\
\hline & & 3 & 7 & 1.6 & 2 & 1.4 & & 1 & 1.4 & 0 & 0 & \\
\hline & & $P$ value & \multicolumn{2}{|c|}{$0.001 *$} & \multicolumn{2}{|c|}{$0.001 *$} & & \multicolumn{2}{|c|}{$0.001 *$} & \multicolumn{2}{|c|}{$0.001 *$} & \\
\hline & \multirow{4}{*}{$\begin{array}{l}\text { Q8 } \\
\text { Toothbrush } \\
\text { renewal } \\
\text { frequency }\end{array}$} & $<3 \mathrm{~m}$ & 95 & 22.2 & 31 & 21.7 & & 12 & 16.9 & 24 & 22 & \multirow{4}{*}{0.001} \\
\hline & & 3-6 m & 112 & 26.2 & 19 & 13.3 & \multirow{3}{*}{0.11} & 24 & 33.8 & 29 & 26.6 & \\
\hline & & $>6 \mathrm{~m}$ & 220 & 51.5 & 93 & 65 & & 35 & 49.3 & 56 & 51.4 & \\
\hline & & P value & \multicolumn{2}{|c|}{$0.001 *$} & \multicolumn{2}{|c|}{$0.001 *$} & & \multicolumn{2}{|c|}{$0.001 *$} & \multicolumn{2}{|c|}{$0.001 *$} & \\
\hline & \multirow{6}{*}{$\begin{array}{l}\text { Q9 } \\
\text { Consultation } \\
\text { in the dental } \\
\text { office }\end{array}$} & Never & 206 & 48.2 & 50 & 35 & \multirow{6}{*}{0.07} & 29 & 40.8 & 19 & 17.4 & \multirow{6}{*}{$0.31 *$} \\
\hline & & $<1$ & 148 & 34.7 & 70 & 49 & & 27 & 38 & 53 & 48.6 & \\
\hline & & $<2$ & 19 & 4.4 & 7 & 4.9 & & 9 & 12.7 & 19 & 17.4 & \\
\hline & & $\begin{array}{l}\text { each } \\
\text { year }\end{array}$ & 17 & 4 & 9 & 6.3 & & 3 & 4.2 & 3 & 2.8 & \\
\hline & & $>2$ years & 37 & 8.7 & 7 & 4.9 & & 3 & 4.2 & 15 & 13.8 & \\
\hline & & $P$ value & & & & & & & & & & \\
\hline & & never & 49 & 47.1 & 202 & 43.3 & & 49 & 64.5 & 60 & 57.7 & \\
\hline & Q7 & 1 & 36 & 34.6 & 192 & 41.2 & & 15 & 19.7 & 27 & 26 & \\
\hline & Dental & 2 & 17 & 16.3 & 65 & 13.9 & -0.1 & 10 & 13.2 & 17 & 16.3 & -0.008 \\
\hline & $\begin{array}{l}\text { orusming } \\
\text { frequency }\end{array}$ & 3 & 2 & 1.9 & 7 & 1.5 & & 2 & 2.6 & 0 & 0 & \\
\hline & & $P$ value & & & & & & & & & & \\
\hline & Q8 & $<3 \mathrm{~m}$ & 20 & 19.2 & 106 & 22.7 & & 12 & 15.8 & 24 & 23.1 & \\
\hline & Toothbrush & 3-6 m & 36 & 33.9 & 104 & 22.1 & & 24 & 31.6 & 29 & 27.9 & 0.04 \\
\hline dft & renewal & $>6 \mathrm{~m}$ & 48 & 46.2 & 257 & 55.2 & $0.15^{*}$ & 40 & 52.6 & 51 & 49 & 0.04 \\
\hline & frequency & $P$ value & & & & & & & & & & \\
\hline & & Never & 70 & 67.3 & 186 & 39.9 & & 22 & 28.9 & 26 & 25 & \\
\hline & & $<1$ & 23 & 22.1 & 196 & 42.1 & & 34 & 44.7 & 46 & 44.2 & \\
\hline & $\begin{array}{l}\text { Q9 } \\
\text { Consultation }\end{array}$ & $<2$ & 5 & 4.8 & 21 & 4.5 & & 8 & 10.5 & 19 & 18.3 & \\
\hline & $\begin{array}{l}\text { in the dental } \\
\text { office }\end{array}$ & $\begin{array}{l}\text { each } \\
\text { year }\end{array}$ & 3 & 2.9 & 22 & 4.7 & $0.22 *$ & 4 & 5.3 & 3 & 2.9 & $0.196^{*}$ \\
\hline & & $>2$ years & 3 & 2.9 & 41 & 8.8 & & 8 & 10.5 & 10 & 9.6 & \\
\hline & & $P$ value & & & & & & & & & & \\
\hline
\end{tabular}




\section{Inter and intra-relationship}

Comparing male \& female in both DMF and dft categories (intra-relationship) revealed significant difference in both categories of DMF and dft except in "with caries" DMF category where the difference was insignificant. Female was significantly higher than male in all as presented in table (4).

Table 4: Comparison between frequency and percentages of distribution of DMF, dft categories among male \& female.

\begin{tabular}{|c|c|c|c|c|c|c|}
\hline & \multicolumn{2}{|c|}{ Male } & \multicolumn{2}{|c|}{ Female } & \multirow{2}{*}{$P$ value } \\
\hline & & $\mathbf{N}$ & $\%$ & $\mathbf{N}$ & $\%$ & \\
\hline \multirow{2}{*}{ DMF } & No caries & 182 & $42.62 \%$ & 245 & $57.38 \%$ & $0.001^{*}$ \\
\hline & With caries & 68 & $47.55 \%$ & 75 & $52.45 \%$ & 0.49 \\
\hline \multirow{2}{*}{ dft } & No caries & 39 & $37.50 \%$ & 65 & $62.50 \%$ & $0.001 *$ \\
\hline & With caries & 211 & $45.28 \%$ & 255 & $54.72 \%$ & $0.006^{*}$ \\
\hline
\end{tabular}

Comparing both groups in each gender in both DMF categories (inter-relationship) revealed significant difference in both categories of DMF \& dft. Group I (6-9 years) was significantly higher than group II ( $>9-12$ years) as presented in table (5).

Table 5: Comparison between frequency and percentages of distribution of DMF categories in sex among different groups in Egyptians

\begin{tabular}{|c|c|c|c|c|c|c|c|}
\hline & & \multirow{2}{*}{ SEX } & \multicolumn{2}{|c|}{ 6-9 years } & \multicolumn{2}{|c|}{$>9-12$ years } & \multirow{2}{*}{$P$ value } \\
\hline & & & $\mathbf{N}$ & $\%$ & $\mathbf{N}$ & $\%$ & \\
\hline \multirow{4}{*}{ DMF } & \multirow{4}{*}{$\begin{array}{c}\text { No caries } \\
\text { with caries }\end{array}$} & Male & 182 & 81.25 & 42 & 18.75 & $0.001 *$ \\
\hline & & Female & 245 & 89.42 & 29 & 10.58 & $0.001 *$ \\
\hline & & Male & 68 & 61.26 & 43 & 38.74 & $0.006^{*}$ \\
\hline & & Female & 75 & 53.19 & 66 & 46.81 & $0.004 *$ \\
\hline \multirow{4}{*}{ dft } & \multirow{4}{*}{$\begin{array}{c}\text { No caries } \\
\text { with caries }\end{array}$} & Male & 39 & 59.09 & 27 & 40.91 & $0.02 *$ \\
\hline & & Female & 65 & 57.02 & 49 & 42.98 & $0.03 *$ \\
\hline & & Male & 211 & 78.44 & 58 & 21.56 & $0.001 *$ \\
\hline & & Female & 255 & 84.72 & 46 & 15.28 & $0.001 *$ \\
\hline
\end{tabular}

\section{Discussion}

Due to the multifactorial nature of dental caries, the salivary properties, oral hygiene frequency, and nutritional status of the patients should be recorded in order to establish their roles as risk factors in the development of dental caries, (Bud el al., 2021).

A multifactorial disease development model is assumed for ECC. Increasing importance is attributed to psychosocial risk factors, such as maternal psychopathologies, educational deficits and poverty (Knoblauch et al., 2019).

This study was conducted to answer an important question "Is there an association between dental caries and oral hygiene and eating habits? which are considered risk factors that may affect both dental and general health conditions of the child with the result of so many difficult burdens on the child ,the family as well as the community in general.

\section{Eating habits}

For association between dental caries \& eating habits, our findings revealed that in Q1 and 2, answer "yes" was significantly higher than "no" in DMF and dft. In Q 3, "2" was significantly the highest in DMF and dft, while "1" was significantly the lowest in all groups except in "no caries" group I in DMF and "with caries" in group II dft, " 3 " was significantly the lowest. Correlation between dental caries and eating habits revealed insignificant correlation in both groups regarding DMF and dft. (Dwyer et al., 2001) in his study found that teenagers who miss breakfast are more likely to snack during the day and snacks have the highest sugar content of any type of meal (that is, breakfast, lunch, dinner or snacks). (Johansson et al., 2010) found that nearly all children (97\%) were reported to eat snacks most days, he found that caries was significantly more prevalent among children who ate chips, dry cereals and dried fruit, but snack like fresh fruit, crackers and yoghurt, however, were not associated with caries, also (Iftikhar et al., 2012) suggest that young children with poor dietary habits consuming snacks frequently were more likely to develop caries as compared to children with no snacking habits. 


\section{Sweat habits}

In question 4 "yes" answer was significantly higher than "no" answer in both categories of DMF and $\mathrm{dft}$ in both groups. In question 5, answer " 1 " was significantly the highest in "no caries" category in group I DMF and group I both categories in dft, answer "3" was significantly the highest in "with caries" category in group I DMF and "with caries" group II in dft. In group II DMF, "1,2" answers were significantly the highest in "no caries", in dft "no caires" group II answer "2" was the highest, while in DMF group I (with caries), dft "with caries) group II answer "1" was significantly the highest while "every week" was significantly the lowest in both groups regarding "no caries" and "with caries" in DMF and dft. In Q6 "chocolate" was significantly the highest in DMF and dft except "others" was significantly the highest in (no caries) category in DMF group II and (more than one type) was the highest in "no caries" dft group II, while "candy" was significantly the lowest in both DMF and dft except in DMF "no caries" group II and in dft "with caries" group II as biscuits was the lowest. Correlation between dental caries and sweet habit showed insignificant correlation in all questions. (Mohamed et al., 2020) in Egypt also found that the frequent consumption of sugars, especially sweets, fruit drinks and desserts could be associated with higher socioeconomic.

\section{Oral hygiene habits}

In Q7, "never" in DMF (64.8\%) and dft (64.5\%) was significantly the highest in all group categories, while "3" was significantly the lowest in DMF and dft in all groups. In Q 8, "> 6 m" was significantly the highest in both groups in DMF and dft, while " $<3$ ") was the lowest in all categories except in DMF and dft "with caries" category group I "3-6 m" was the lowest "3-6" was the lowest in all DMF groups except (no caries) of group I " $<3$ " was significantly the lowest $(22.2 \%)$, also " $<3$ " was the lowest in both groups of dft in Egyptians except (with caries) of group I as "3-6 m" was the lowest (22.1\%). For Sudanese in DMF group I " $<3 \mathrm{~m}$ " was the lowest in both categories (27.1\%) but "3-6m" was the lowest in group II both categories (16.4\%), for dft group I, " $>6 \mathrm{~m}$ " was the lowest in no caries $(25.2 \%)$ and " $<3 \mathrm{~m}$ " in with caries $(24.1 \%)$ but " $3-6 \mathrm{~m}$ " was the lowest in both categories of group II (14.8\%). In Q 9, DMF "never" was significantly the highest in both groups "no caries" category of both groups and in dft "no caries" group I, while " $<1$ " was the highest in both groups "with caries" category of DMF (49\%) and all other categories of dft (44.2\%), while "each year" was significantly the lowest in all DMF and dft except DMF and dft in "with caries" group I as ">2 years" was the lowest $(4.9 \%)$. There was insignificance correlation between DMF and dft with all questions except Q (9) in DMF group II and in $\mathrm{dft}$ both groups and Q (8) in dft group I. Our finding goes with (Ghasemianpou et al., 2019; Kumar et al., 2016), they found that reverse associations were found between higher frequency of tooth brushing with dental caries indices in both age groups.

\section{Intra and interrelationship of dental caries}

By comparing between group I (6-9) and group II (9-12) ( inter-relationship), it was found that group I was significantly higher than group II, our result goes with (Mulu et al., 2014) that found that the majority $(75 \%)$ had primary tooth decay. This finding could be due to presence of many primary teeth present in the oral cavity compared to permanent teeth.

By comparing between sex (intra-relationship), it was found that female was significantly higher than male in all except (>9-12 years) age range in (no caries category of DMF and (with caries category of dft).

\section{Limitations of this study}

Covid 19 pandemic was one of the most difficult challenges we met which was a barrier for our entrance in schools.

\section{Conflict of interests}

There was no conflict of interests in this study.

\section{Conclusion}

It can be concluded that there is relationship between dental caries, eating and oral hygiene habits. In Q 8 (tooth brushing renewal frequency) in dft group I and Q 9 (consultation in dental office) the 
correlation was significant weak positive, while all other questions were insignificant. Group I (6-9) was significantly higher than group II, females were significantly higher than males.

\section{References}

Ahmed, T.E.S., and A.H. Abuaffan, 2015. Correlation between body mass index and dental caries among a sample of sudanese children Braz. Dent. Sci., 18(3): 42-51.

Bahrololoomi, Z., F.F. Ardakani, and F.D. Ardakani, 2017. Body mass index and dental caries in children. Int. J. Sch. Health, 4:1-5.

Baccouche, F.M., A. Sebai, M.A. Ouanane, B. Ahlem, and M.F. Fethi, 2017. Relationship Between Dental Caries and Body Mass Index in Tunisian Children. International Annals of Medicine; 1(9).

Bud, E.S., C.I. Bica and O.E. Stoica, et al., 2021. Observational Study Regarding the Relationship between Nutritional Status, Dental Caries, Mutans Streptococci, and Lactobacillus Bacterial Colonies. International journal of environmental research and public health; 18, (3551), 1-12, https://doi.org/10.3390/ijerph18073551.

Dwyer, J., M. Evans and E. Stone et al., 2001. Dietary intake and food patterns of Zuni adolescents. Research and professional briefs., 101(7): 798-802.

Ghasemianpour, M., S. Bakhshandeh, and A. Shirvani, 2019. Dental caries experience and socioeconomic status among Iranian children: a multilevel analysis. BMC Public Health, 19(1569):1-8,

Iftikhar, A., M. Muneeza Zafar, and M.U. Kalar, 2012. The relationship between snacking habits and dental caries in school children. International Journal of Collaborative Research on Internal Medicine \& Public Health, 4(12): 1943-1951.

Johansson, I., P. Holgerson and N. Kressin, 2010. Snacking Habits and Caries in Young Children. Caries research, 44:421-430, DOI: 10.1159/000318569.

Kumar, S., J. Tadakamadla, and N. Johnson, 2016. Effect of Toothbrushing frequency on incidence and increment of dental caries: a systematic review and metaanalysis. J. Dent. Res., 95(11):1230-6.

Knoblauch, U.R. and K. Weidner, 2019. The association between socioeconomic status, psychopathological symptom burden in mothers, and early childhood caries of their children. PLOS ONE; 14(10): 1-14, https://doi.org/10.1371/journal.pone.0224509.

Machiulskienea, V., G. Campusb, J. Carvalho, et al., 2020. Terminology of Dental Caries and Dental Caries Management: Consensus Report of a Workshop Organized by ORCA and Cariology Research Group of IADR. Caries Res., 54:7-14, DOI: 10.1159/000503309.

Mulu W., T. Demilie and M. Yimer et al., 2014. Dental caries and associated factors among primary school children in Bahir Dar city: a cross-sectional study. BMC Research Notes; 7(949), 1-7.

Mohamed Y., H. Sabry and M. Mohammed, 2020. Relationship between snaking habits and caries experience a comparative study between Egyptians and Kuwaiti children. Egyptian dental journal, 66: 57-64.

Sakeenabia, B., H.S. Swamyb, and R.N. Mohammed, 2012. Association between Obesity, Dental Caries and Socioeconomic Status in 6- and 13-year-old School Children. Oral Health Prev. Dent., 10(3): 231-241.

World Health Organization, 2013. Oral health survey, Basic Methods, WHO. 